\title{
Spermine impairs biofilm formation by Neisseria gonorrhoeae
}

\author{
Maira Goytia ${ }^{1}$, Vijaya L. Dhulipala ${ }^{1}$, and William M. Shafer ${ }^{1,2,{ }^{*}}$ \\ ${ }^{1}$ Department of Microbiology and Immunology, Emory University School of Medicine, Atlanta, \\ Georgia 30322 \\ ${ }^{2}$ Laboratory of Bacterial Pathogenesis, Veterans Affairs Medical Center (Atlanta), Decatur, \\ Georgia 30033 USA
}

\begin{abstract}
Neisseria gonorrhoeae is a strict human pathogen that causes the sexually transmitted infection termed gonorrhea. Recent reports indicate that gonococci can form a biofilm in vivo and under laboratory conditions. It is unclear, however, if formation of such biofilms or their dispersal are influenced by host factors that would be encountered during infection. In this respect, physiological levels of polyamines have been reported to influence biofilm structures formed by other Gram-negative bacteria as well those formed by Gram-positive bacteria and can cause dispersal of a biofilm formed by Bacillus subtilis. Based on these reports, we examined the influence of polyamines on gonococcal biofilm formation and their dispersal. We now report that physiological levels of certain polyamines, notably spermine, can significantly decrease the capacity of gonococci to form a biofilm, but do not cause dispersal of a pre-formed biofilm. In the context of natural gonococcal infection, the presence of physiological levels of spermine may be antagonistic for gonococci to form a biofilm and this may be of importance in the spread of the pathogen from a localized region.
\end{abstract}

\section{Introduction}

Neisseria gonorrhoeae is a sexually-transmitted obligate human pathogen. Its disease, gonorrhea, is estimated to affect over 700,000 women and men in the United States yearly (Weinstock, et al., 2004) and 106 million people worldwide (Velicko \& Unemo, 2009).

Alarming reports of increasing levels of resistance to antibiotics and of increasing numbers of multi-drug resistant strains suggest that gonorrhea could soon become untreatable if new antibiotics are not developed or if combination therapies of existing antibiotics become less effective over time (Ohnishi, et al., 2011).

Laboratory studies typically employ planktonic bacteria, but since gonococci form biofilms in vivo it is important to learn how this structure is formed as they could significantly influence pathogenesis and host responses. Since gonococcal biofilms formed under laboratory conditions resemble those formed by other bacteria (Greiner et al., 2005; Donlan \& Costerton, 2002), it is now possible to study aspects of gonococcal biology and hostpathogen interaction in the context of gonococci in biofilms versus their planktonic state. Recently, investigators have questioned whether host-derived factors can influence biofilm formation or their dispersal. In this regard, the influence of polyamines has received attention. These small cationic molecules can have antibacterial action against a number of human pathogens, but gonococci are resistant to many polyamines (Goytia \& Shafer, 2010). Instead, we have shown that polyamines such as spermine and spermidine can coat the

*Corresponding author: Mailing address: Department of Microbiology and Immunology, Emory University School of Medicine, 1510 Clifton Road, NE, Atlanta, GA 30322. Phone: (404) 728-7688. Fax: (404) 329-2210. wshafer@emory.edu. 
surface of gonococci and protect them from cationic antimicrobial peptides and complement-mediated killing by human serum (Goytia \& Shafer, 2010). Recent studies have documented the capacity of polyamines to either impair or enhance biofilm formation or their dispersal. Interestingly, in studies using Bacillus subtilis, Escherichia coli and Staphylococcus aureus, norspermidine was found to block biofilm formation and trigger dispersal of a biofilm formed by B. subtilis (Kolodkin-Gal, et al., 2012). Given the opposing antibacterial effects of polyamines on gonococci versus other bacteria, we asked whether gonococcal biofilms would be influenced by polyamines in a manner resembling other bacteria. We now report that physiological concentrations of certain polyamines (spermine and spermidine) that would be encountered by gonococci during infection can impair biofilm formation, but do not stimulate dispersal of a pre-formed biofilm.

\section{Materials and Methods}

\section{Bacterial strains, culture conditions, and chemical compounds}

N. gonorrhoeae strain FA19 was the primary strain used in this study (Sarubbi, et al., 1974). However, some experiments also employed a previously described (Goytia \& Shafer, 2010) mutant of strain FA19 lacking the potHI genes which encode components of a polyamine transporter system. Cultures were grown on gonococcal medium base (GCB) agar (Difco Laboratories, Detroit, MI) containing glucose and iron supplements at $37^{\circ} \mathrm{C}$, under $4.3 \%$ (v/ v) $\mathrm{CO}_{2}$, or in GCB broth with supplements and sodium bicarbonate as described previously (Shafer, et al., 1984). All chemicals were purchased from Sigma Biochemical (St. Louis, MO); polyamines were obtained in powder form as hydrochloride salt.

\section{Biofilm formation and dispersion assays}

Biofilm formation assays were performed as a modified version of the protocol originally developed by O'Toole (O'Toole \& Kolter, 1998). Briefly, gonococci were grown in GCB broth with supplements as described above, until they reached $\mathrm{OD}_{600 \mathrm{~nm}}$ of 0.4 Units of Absorbance (UA). Cells were then diluted 1:100 in biofilm medium (0.1× GCB in phosphate buffered saline [PBS] with full strength supplements) with or without additional polyamines; and $10^{7}$ cells (100 $\mu \mathrm{L} /$ well) were distributed in 96-well plates (Corning, \#3370). Polyamines were tested at $0.5 \mathrm{mM}$ and $4 \mathrm{mM}$, which are physiologically-relevant concentrations for spermine and spermidine in the male urogenital tract (UGT) (Bachrach, 1970). Concentrations of putrescine and cadaverine range between 0.5 and $1 \mathrm{mM}$ in the UGT (Bachrach, 1970). Peripheral wells of the microtiter tray were filled with $200 \mu \mathrm{L}$ of double distilled (dd) $\mathrm{H}_{2} \mathrm{O}$, and plates were wrapped in Saran wrap to prevent evaporation. Plates were incubated at $37^{\circ} \mathrm{C}$ under $4.3 \% \mathrm{CO}_{2}$ for $20 \mathrm{~h}$ without shaking. After incubation, supernatants from each well were sampled to quantify viable planktonic gonococci; viability was assessed by dilution plating onto GCB agar and colony forming units were enumerated after incubation for $24 \mathrm{~h}$ at $37^{\circ} \mathrm{C}$ under $4.3 \% \mathrm{CO}_{2}$. The microtiter plates were washed once in $\mathrm{dd}_{2} \mathrm{O}$, and then air-dried overnight. Biofilms were stained with $65 \mu \mathrm{L}$ of $0.1 \%$ (w/v) crystal violet. The plates were then incubated for $15 \mathrm{~min}$ at room temperature, washed 5 times in $\mathrm{ddH}_{2} \mathrm{O}$, and dried overnight at room temperature. Stained biofilms were dissolved with $125 \mu \mathrm{L}$ of $95 \%$ ethanol and shaken until the crystal violet had completely dissolved. Plates were immediately read at $570 \mathrm{~nm}$ using a Perkin-Elmer Victor $\mathrm{X}^{3}$ plate-reader $(0.3$ sec/well). Results are reported as averages (+/- standard deviation) of at least three independent experiments and statistical differences, using Student's $t$-test, were deemed significant at $p<0.5$.

In order to examine dispersion of biofilms by polyamines, we modified a previously described assay (Kolodkin-Gal, et al., 2012). Briefly, biofilms were allowed to form as described above for $18 \mathrm{~h}$, and then $100 \mu \mathrm{L}$ of polyamines (spermine, norspermidine or 
putrescine) were added to a final concentration of $0.5 \mathrm{mM}$. In other biofilm wells in the same experiment, DNase I ( 2 units $/ \mathrm{ml})$ or proteinase $\mathrm{K}(0.08 \mu \mathrm{g} / \mathrm{ml})$ was added. After sixty minutes of incubation at $37^{\circ} \mathrm{C}$ the supernatant of the biofilm was removed and the remaining biofilm was examined as described above.

\section{Scanning electron microscopy}

Biofilms were prepared as described above with a few modifications. At the beginning of the experiment, sterile silicon chips were introduced in the wells of a 24-well microtiter plate and $10^{8}$ gonococci in $1 \mathrm{ml}$ were added with or without $4 \mathrm{mM}$ spermine. The plates were then incubated for $40 \mathrm{~h}$ at $37^{\circ} \mathrm{C}$ under $4.3 \% \mathrm{CO}_{2}$. The growth medium was replaced by a fixative agent ( $2 \%$ paraformaldehyde, $2 \%$ glutaraldehyde in $0.15 \mathrm{mM}$ cacodylate buffer, $\mathrm{pH}$ 7.4). After $18 \mathrm{~h}$ of incubation at room temperature, the silicon chips were washed twice in $0.15 \mathrm{mM}$ cacodylate buffer ( $\mathrm{pH}$ 7.4) for $10 \mathrm{~min}$ and this was followed by osmium fixation $\left(1 \% \mathrm{OsO}_{4}, 1.5 \% \mathrm{~K}_{3} \mathrm{Fe}(\mathrm{CN})_{6}\right.$ in $0.15 \mathrm{M}$ cacodylate buffer, $\left.\mathrm{pH} 7.4\right)$ for $1 \mathrm{~h}$ at room temperature. The silicon chips were then washed twice in $\mathrm{ddH}_{2} \mathrm{O}$, and then dehydrated by a series of graded ethanol washes $(25 \%, 50 \%, 70 \%, 95 \%, 3$ times $100 \%)$ at room temperature. After a run of critical point drying, the silicon chips were coated with chromium and observed under a Topcon DS-130F (Topcon Technologies, Inc.) scanning electron microscope, using $5 \mathrm{keV}$.

\section{Results and Discussion}

The human UGT is rich in polyamines such as spermine and spermidine and these molecules can protect gonococci from host antimicrobials (Goytia \& Shafer, 2010). Because biofilm formation by other bacteria can be impacted differently by distinct polyamines, we tested a panel of polyamines against gonococci for their capacity to reduce biofilm formation or trigger their dispersal. We first tested biofilm formation by wild-type strain FA19 in presence or absence of polyamines (spermine, spermidine, putrescine, cadaverine, and norspermidine). We were specifically interested in norspermidine as it was shown to inhibit biofilm formation by three different bacteria and to trigger biofilm dispersal in $B$. subtilis (Kolodkin-Gal et al., 2012). In pilot experiments, we found that spermine, spermidine, putrescine, and cadaverine at concentrations of $0.5 \mathrm{mM}$ or $4 \mathrm{mM}$, or norspermidine at $0.5 \mathrm{mM}$ had no impact on viability of planktonic gonococci; however, norspermidine at a concentration of $4 \mathrm{mM}$ exerted considerable anti-gonococcal activity in vitro. With respect to the ability of these polyamines to influence biofilm formation, we observed that spermine was the most effective polyamine in reducing biofilm formation under the conditions employed (Fig. 1). In order to test whether polyamine transport was required for reduction of biofilm formation, we used a mutant of strain FA19 that lacks the potHI genes (Goytia \& Shafer, 2010), which form part of the gonococcal polyamine transport system apparatus, and is impaired in spermine and spermidine transport (L. Hawel III, personal communication). With this mutant, we found that under control conditions or in the presence of $4 \mathrm{mM}$ spermine the extent of biofilm formation was similar to the wild-type strain (Fig. 2). These results suggest that the impact of spermine on biofilm formation is independent of polyamine transport and more likely reflects the ability of spermine and other biofilm-inhibiting polyamines to interact with the gonococcal surface and disrupt bacterial aggregation events necessary for biofilm formation.

In order to learn if differences exist in biofilm architecture due to spermine (the most effective polyamine in reducing biofilm formation [Fig. 1]), we employed scanning electron microscopy (SEM). We found that in the absence of spermine, gonococci formed tridimensional structures (Fig. 3) that resembled those previously reported (Greiner, et al., 2005). These biofilm formations revealed gonococci enclosed in a fibrous matrix (Fig. 3, A, C), where channels were visualized at higher magnifications (Fig. 3B, D). In contrast, SEM 
examination of gonococci incubated in the presence of spermine, revealed that the biofilm matrix formed by the control was rare and the channels were more difficult to observe even at higher magnifications (Fig. 3, E, F). Indeed, the tridimensional structures of these spermine-treated gonococci were sparse, contained less bacteria, and were not uniformly distributed.

The capacity of polyamines to influence biofilm architecture led us to test whether this matrix could be disrupted upon addition of polyamines. Such a disruptive effect could enhance the otherwise natural process of dispersal. Indeed, one polyamine (norspermidine) has been documented to trigger dispersal of a biofilm formed by B. subtilis (Kolodkin-Gal et al., 2012). Accordingly, we tested whether three polyamines (spermine, norspermidine and putrescine) could trigger dispersal of a pre-formed biofilm. As controls, we also tested the ability of DNase I and Proteinase K to disrupt biofilms since such biofilms were reported to contain extracellular gonococcal DNA and protein within the matrix (Falsetta et al., 2011). In contrast to the action of DNase I and Proteinase K, we did not observe dispersal of preformed biofilms in the presence of any of the polyamines (Fig. 4).

Gonorrhea is an ancient human disease (Edwards \& Apicella, 2004) and the gonococcus has likely survived as a human pathogen over the millennia due to its ability to adapt to the hostile environments that it encounters as it infects the male or female mucosae. Thus, it is not surprising that the gonococcus has developed mechanisms to resist the initial host defenses of the innate immunity systems that it encounters early during infection (Joiner, et al., 1983, Shafer, et al., 1986, Shafer, et al., 1998). Less well-studied is their ability to interact as a community on mucosal surfaces, but recent evidence strongly supports the notion that like other bacteria gonococci can form a biofilm in vivo (Steichen, et al., 2008). In this respect, an examination of ex vivo endocervical biopsies revealed that $30 \%$ of these contained gonococci interacting as a biofilm. That gonococci can form a biofilm using laboratory techniques is supported by the work of Greiner et al.,(2005). Additionally, genes important for the formation of biofilms have been identified (Falsetta, et al., 2011).

Laboratory techniques for evaluating biofilm formation often do not include host-derived agents that might negatively or positively impact biofilm formation and/or dispersion. Our work suggests that physiologic levels of polyamines known to exist in the male UGT (e.g., spermine and spermidine) could significantly influence the ability of goonococci to form a biofilm. In vivo, bursts of spermine are likely to happen in the female UGT early during infection as sperm contains up to $15 \mathrm{mM}$ spermine (and other related polyamines at lower concentrations) (Bachrach, 1970). Since biofilms are often associated with enhanced resistance of bacteria to antibiotics (Stewart \& Costerton, 2001) and the ability to cause a chronic infection (Donlan \& Costerton, 2002), the ability of polyamines to reduce biofilm formation may be more important for the spread of gonococci along mucosal surfaces. Our earlier finding that polyamine-coating can render the bacteria more resistant to cationic antimicrobial peptides could provide these gonococci with an advantage in vivo as they could subvert innate host defenses.

A growing body of literature supports the notion that polyamines can impact biofilm formation by bacterial pathogens. Along with our gonococcal work, others have reported that polyamines affect biofilm formation by several bacteria including B. subtilis, $E$. coli, $S$. aureus, Yersinia pestis (Patel, et al., 2006) and Vibrio cholerae. It is not only host-derived polyamines that can influence biofilms. Kolodkin-Gal et al. (2012) demonstrated that norspermidine, a polyamine exclusively produced by bacteria, can both inhibit biofilm formation and trigger its dispersal. Note, however, that polyamines can have different effects on biofilm formation or dispersal depending on the target bacteria. For instance, under laboratory conditions, norspermidine effectively blocks biofilm formation by $B$. subtilis and 
can cause its dispersal (Kolodkin-Gal, et al., 2012), yet is unable to inhibit gonococcal biofilm formation or trigger its dispersal. Finally, norspermidine, which reduces biofilm formation by $B$. subtilis, can act as an enhancer of biofilm formation by $V$. cholerae (Karatan, et al., 2005). Continued research dealing with how polyamines impact biologic properties of bacteria, including biofilm formation and dispersal, associated with pathogenesis may provide novel strategies for development of new therapeutics that counteract the increasing problem of antibiotic resistance expressed by many bacterial pathogens including the gonococcus.

\section{Acknowledgments}

We thank E.R. Wright and J.V. Taylor from the RPAI Electron Microscopy Core Facility at Emory University for assistance with SEM, Y. Zalucki and C. Rouquette-Loughlin for helpful discussions, M. Apicella for advice regarding gonococcal biofilms and L. Pucko for help in manuscript preparation. This work was supported by NIH grant U19 AI0131496 (P.F. Sparling, University of North Carolina School of Medicine) and a VA Merit Award to W.M.S. from the Medical Research Service of Department of Veterans Affairs. W.M.S. is also the recipient of a Senior Research Career Award from the Medical Research Service of the Department of Veterans Affairs.

\section{References}

Bachrach U. Metabolism and function of spermine and related polyamines. Annu Rev Microbiol. 1970; 24:109-134. [PubMed: 4927131]

Donlan RM, Costerton JW. Biofilms: survival mechanisms of clinically relevant microorganisms. Clin Microbiol Rev. 2002; 15:167-193. [PubMed: 11932229]

Edwards JL, Apicella MA. The molecular mechanisms used by Neisseria gonorrhoeae to initiate infection differ between men and women. Clin Microbiol Rev. 2004; 17:965-981. [PubMed: 15489357]

Falsetta ML, Steichen CT, McEwan AG, et al. The composition and metabolic phenotype of Neisseria gonorrhoeae biofilms. Front Microbiol. 2011; 2:75. [PubMed: 21833322]

Goytia M, Shafer WM. Polyamines can increase resistance of Neisseria gonorrhoeae to mediators of the innate human host defense. Infect Immun. 2010; 78:3187-3195. [PubMed: 20439477]

Greiner LL, Edwards JL, Shao J, Rabinak C, Entz D, Apicella MA. Biofilm formation by Neisseria gonorrhoeae. Infect Immun. 2005; 73:1964-1970. [PubMed: 15784536]

Joiner KA, Warren KA, Brown EJ, Swanson J, Frank MM. Studies on the mechanism of bacterial resistance to complement-mediated killing. IV. C5b-9 forms high molecular weight complexes with bacterial outer membrane constituents on serum-resistant but not on serum-sensitive Neisseria gonorrhoeae. J Immunol. 1983; 131:1443-1451. [PubMed: 6411816]

Karatan E, Duncan TR, Watnick PI. NspS, a predicted polyamine sensor, mediates activation of Vibrio cholerae biofilm formation by norspermidine. J Bacteriol. 2005; 187:7434-7443. [PubMed: 16237027]

Kolodkin-Gal I, Cao S, Chai L, Bottcher T, Kolter R, Clardy J, Losick R. A self-produced trigger for biofilm disassembly that targets exopolysaccharide. Cell. 2012; 149:684-692. [PubMed: 22541437]

O'Toole GA, Kolter R. Initiation of biofilm formation in Pseudomonas fluorescens WCS365 proceeds via multiple, convergent signalling pathways: a genetic analysis. Mol Microbiol. 1998; 28:449_ 461. [PubMed: 9632250]

Ohnishi M, Golparian D, Shimuta K, et al. Is Neisseria gonorrhoeae initiating a future era of untreatable gonorrhea?: detailed characterization of the first strain with high-level resistance to ceftriaxone. Antimicrob Agents Chemother. 2011; 55:3538-3545. [PubMed: 21576437]

Patel CN, Wortham BW, Lines JL, Fetherston JD, Perry RD, Oliveira MA. Polyamines are essential for the formation of plague biofilm. J Bacteriol. 2006; 188:2355-2363. [PubMed: 16547021]

Sarubbi FA Jr, Blackman E, Sparling PF. Genetic mapping of linked antibiotic resistance loci in Neisseria gonorrhoeae. J Bacteriol. 1974; 120:1284-1292. [PubMed: 4279905]

Shafer WM, Onunka V, Hitchcock PJ. A spontaneous mutant of Neisseria gonorrhoeae with decreased resistance to neutrophil granule proteins. J Infect Dis. 1986; 153:910-917. [PubMed: 3084666] 
Shafer WM, Guymon LF, Lind I, Sparling PF. Identification of an envelope mutation (env-10) resulting in increased antibiotic susceptibility and pyocin resistance in a clinical isolate of Neisseria gonorrhoeae. Antimicrob Agents Chemother. 1984; 25:767- 769. [PubMed: 6430226]

Shafer WM, Qu X, Waring AJ, Lehrer RI. Modulation of Neisseria gonorrhoeae susceptibility to vertebrate antibacterial peptides due to a member of the resistance/nodulation/division efflux pump family. Proc Natl Acad Sci U S A. 1998; 95:1829-1833. [PubMed: 9465102]

Steichen CT, Shao JQ, Ketterer MR, Apicella MA. Gonococcal cervicitis: a role for biofilm in pathogenesis. J Infect Dis. 2008; 198:1856-1861. [PubMed: 18973432]

Stewart PS, Costerton JW. Antibiotic resistance of bacteria in biofilms. Lancet. 2001; 358:135-138. [PubMed: 11463434]

Velicko I, Unemo M. Increase in reported gonorrhoea cases in Sweden, 2001 - 2008. Euro Surveill. 2009:14.

Weinstock H, Berman S, Cates W Jr. Sexually transmitted diseases among American youth: incidence and prevalence estimates, 2000. Perspect Sex Reprod Health. 2004; 36:6-10. [PubMed: 14982671] 


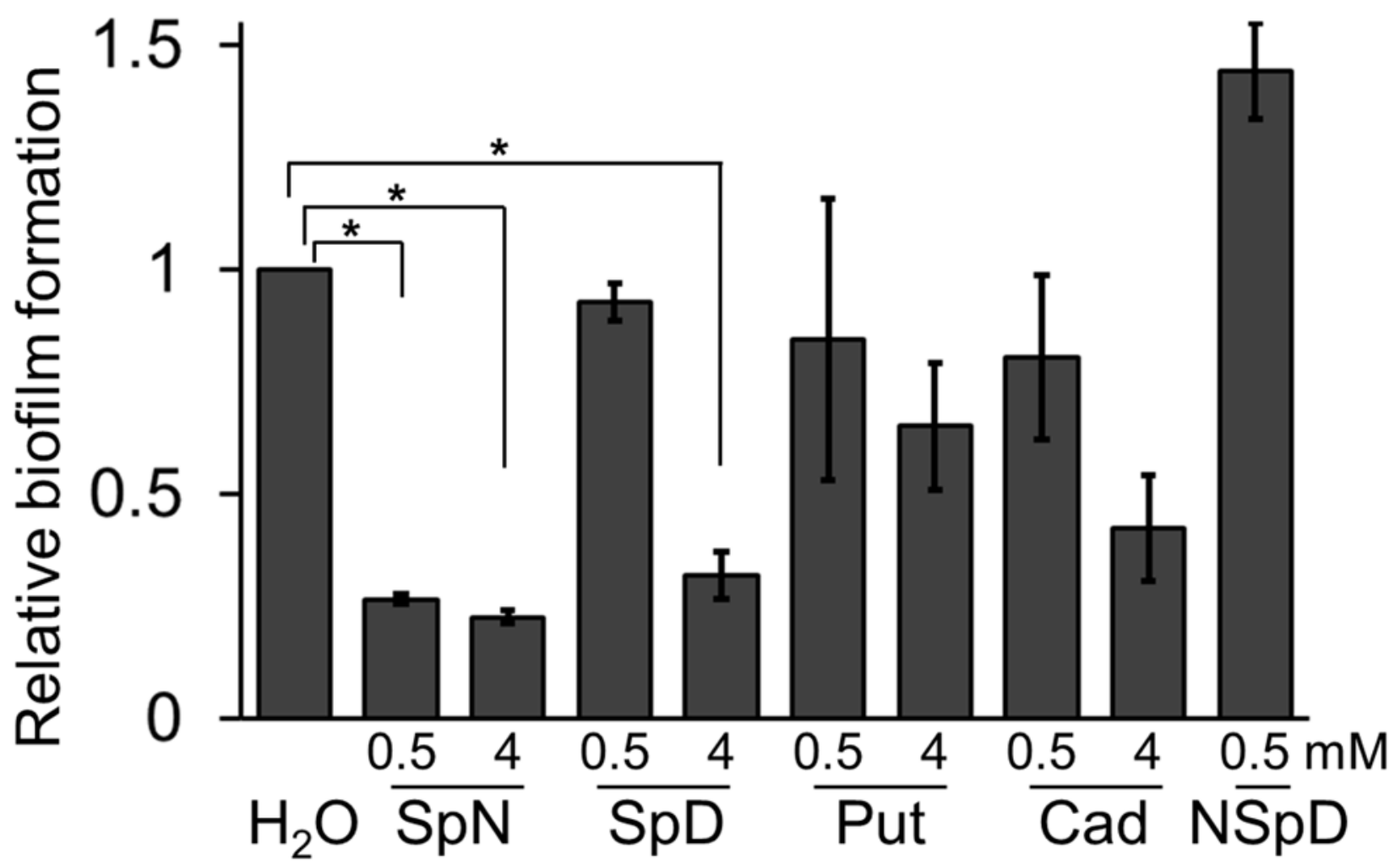

Figure 1. Extracellular spermine impairs biofilm formation by $N$. gonorrhoeae

$N$. gonorrhoeae strain FA19 $\left(10^{8} \mathrm{CFU} / \mathrm{ml}\right)$ were incubated in 96 -well plates in the presence of increasing concentrations of polyamines. Error bars show SDs of 3 independent experiments. SpN, spermine; $\mathrm{SpD}$, spermidine; Put, putrescine; Cad, cadaverine; NSpD, norspermidine. $(* p<0.05)$ 


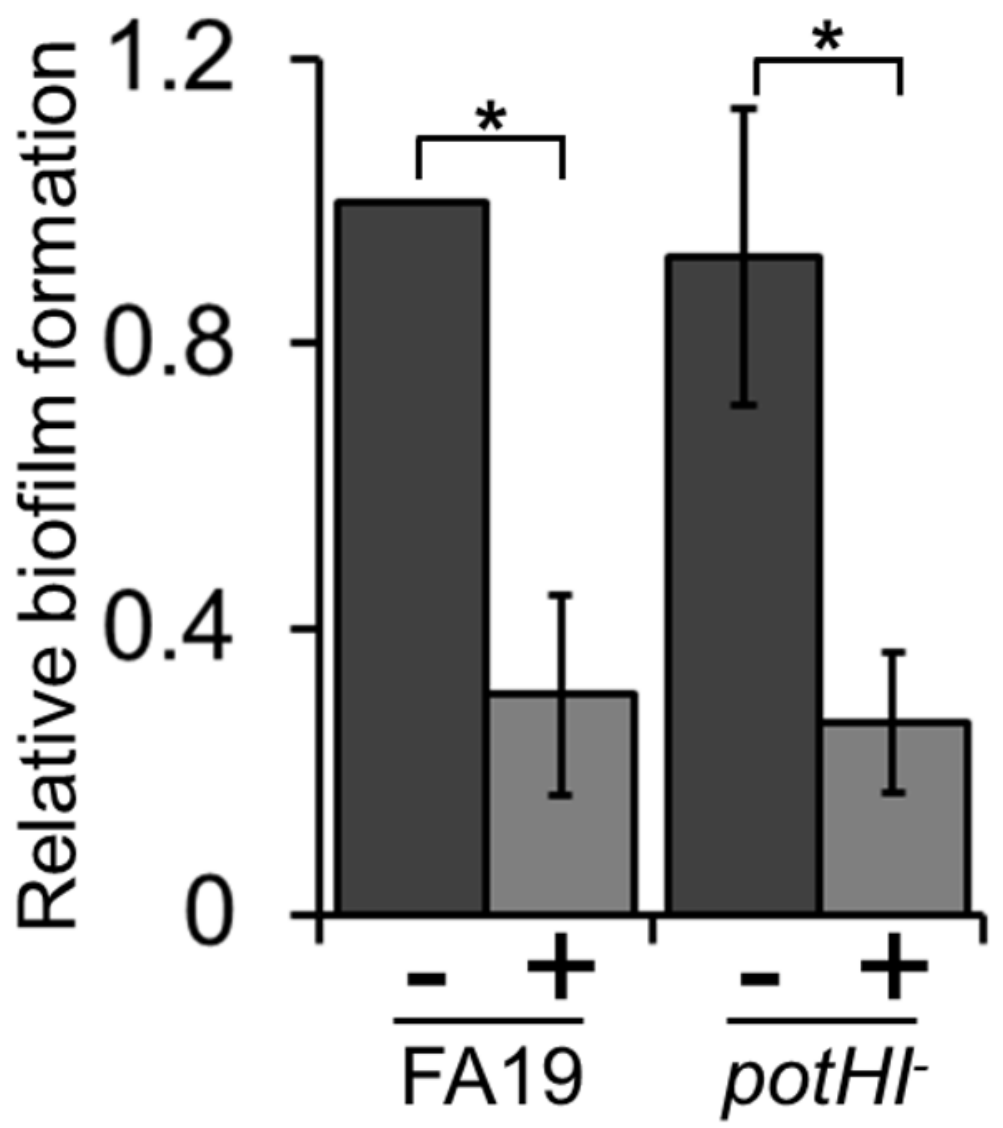

Figure 2. Spermine inhibits biofilm formation by a gonococcal polyamine transport deficient mutant

Biofilm growth medium supplemented with $4 \mathrm{mM}$ spermine (+) prevented the formation of biofilms by wild-type strain or its isogenic potHI-negative mutant strain of the polyamine transporter channel, when compared to growth medium without spermine (-). Wild-type and mutant strains were affected to the same extent. Error bars show SDs of 3 independent experiments $(* p<0.05)$. 
A

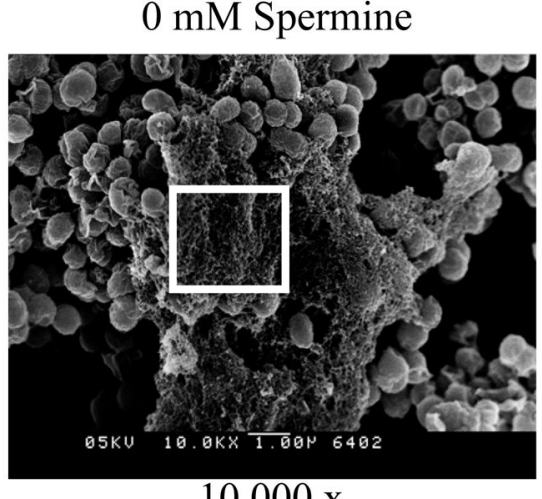

C

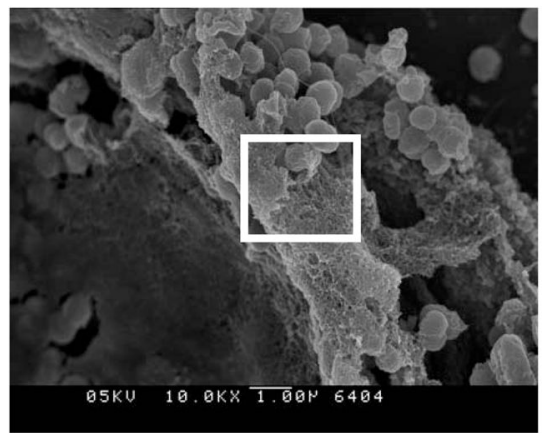

$10,000 \mathrm{x}$

E

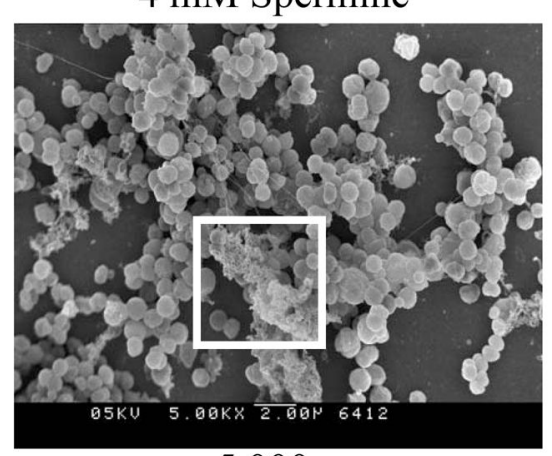

$5,000 \mathrm{x}$
B

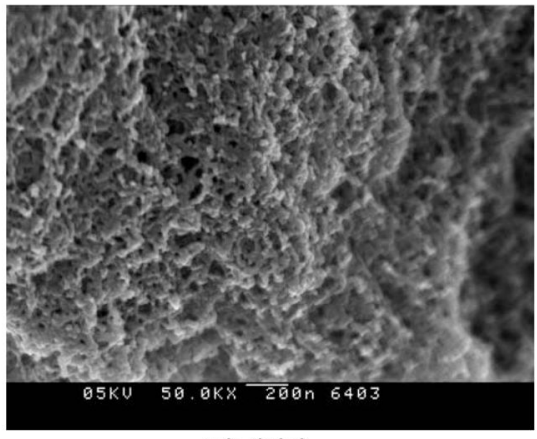

$50,000 \times$

D

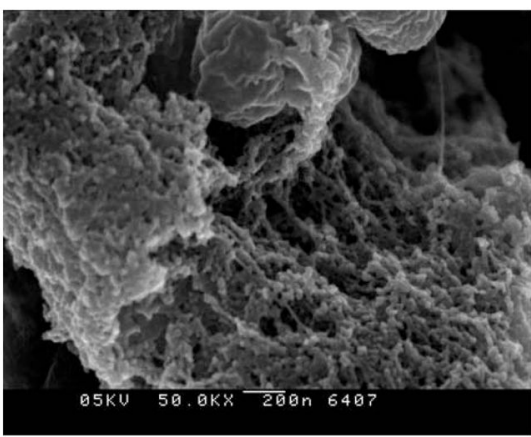

$50,000 \times$

F

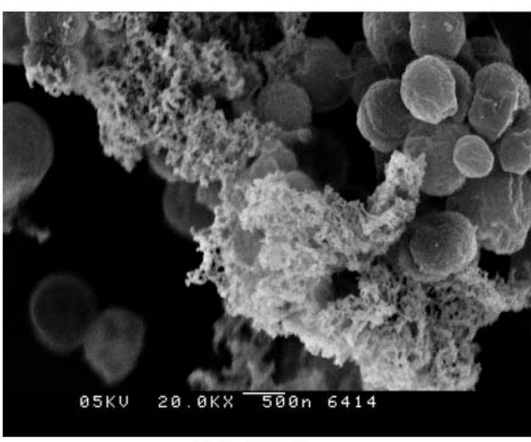

$20,000 \mathrm{x}$

Figure 3. Scanning electron microscopy images of biofilm formations by strain FA19 with or without added spermine

Biofilm formations by strain FA19, after $40 \mathrm{~h}$ of culture, (A-D) without added polyamine to the growth medium or (E, F) with $4 \mathrm{mM}$ spermine added to the growth medium.

(Magnifications are as follows: A, C: 10,000x, B, D: 50,000x, E: 5,000x, F: 20,000x). The white squares inside images $\mathrm{A}, \mathrm{C}$ and $\mathrm{E}$ identify the section magnified in $\mathrm{B}, \mathrm{D}$ and F, respectively. 


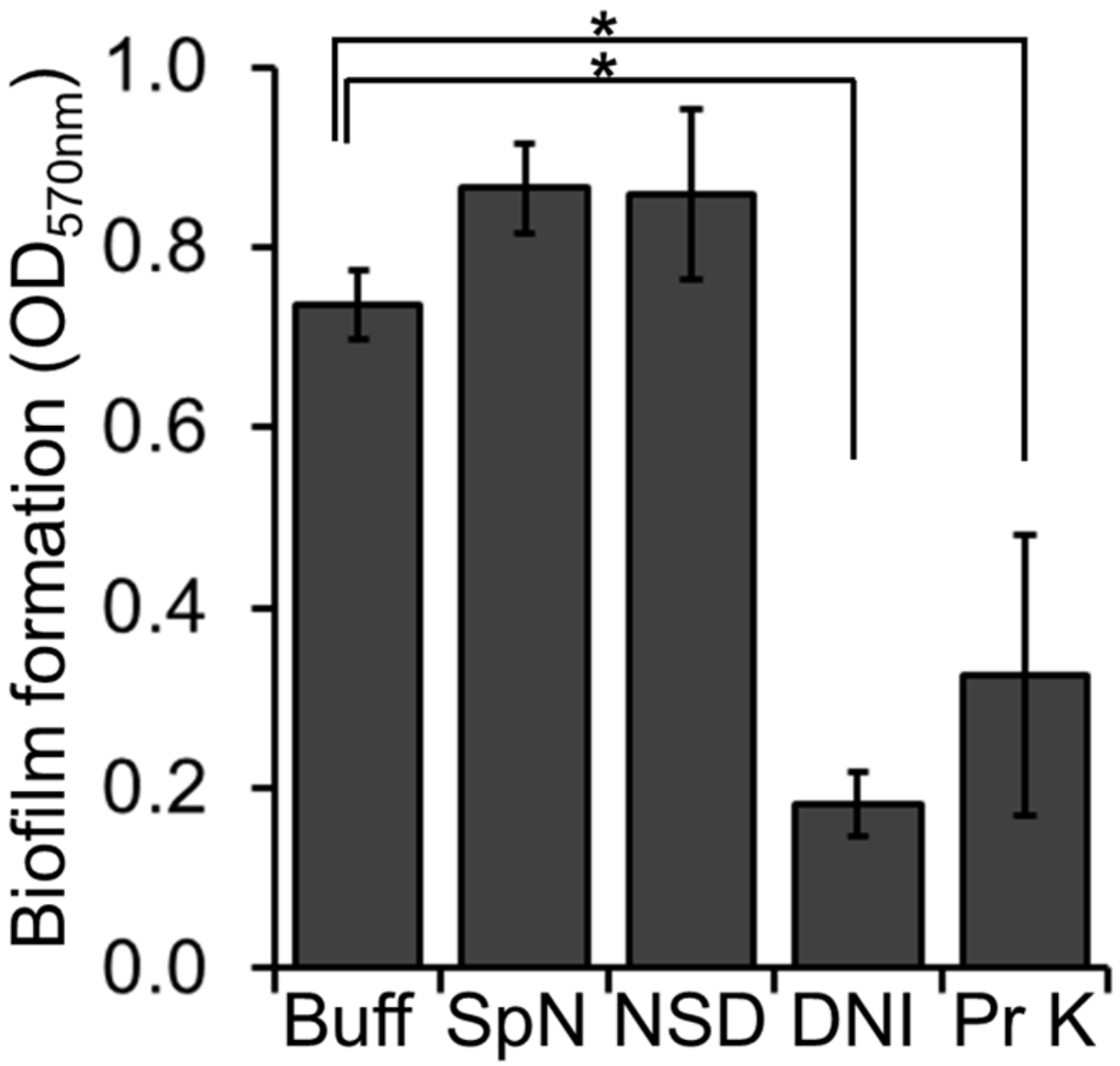

Figure 4. Neither spermine nor norspermidine trigger dispersal of pre-formed biofilms Pre-formed biofilms were challenged with spermine or norspermidine (at $0.5 \mathrm{mM}$ ) or with DNase I ( $2 \mathrm{U} / \mathrm{mL})$ or with proteinase $\mathrm{K}(0.08 \mu \mathrm{g} / \mathrm{mL})$, during $60 \mathrm{~min}$. DNase I and proteinase $\mathrm{K}$ were used as positive control of dispersion since the biofilm matrix contains extracellular DNA and proteins. SpN, spermine; NSD, norspermidine; DNI, DNase I; Pr K, proteinase $\mathrm{K}$. 